Jotzo, F. and Löschel, A. (2014), 'Emissions trading in China: Emerging experiences and international lessons', Energy Policy 75: 3-8.

Overview of Energy Policy special issue 'Emissions trading in China' (ed: Löschel and Jotzo).

Pre-publication version.

\title{
Emissions trading in China: emerging experiences and international lessons
}

\author{
Frank Jotzo ${ }^{1}$ and Andreas Löschel ${ }^{1,2,3,4}$ \\ ${ }^{1}$ Crawford School of Public Policy, Australian National University, Canberra, ACT 0200, Australia \\ 2 University of Münster (Department of Economics), 48143 Münster, Germany \\ ${ }^{3}$ University of International Business and Economics, Beijing 100029, China \\ ${ }^{4}$ Centre for European Economic Research (ZEW), Mannheim, Germany
}

\section{Abstract}

China has implemented emissions trading schemes in seven cities and provinces, and is planning a national cap-and-trade scheme. The seven pilot schemes show marked differences in design and operate in very diverse economic circumstances. Challenges encountered in the pilot schemes include the risk of over-allocation of emissions permits, unpredictable underlying growth trends, robust measurement and verification procedures, and the interaction with regulation in the energy sector. In addition, experiences from developed countries' emissions trading schemes, in particular the EU ETS, can help inform the decisions about the design of a future Chinese national scheme. Policymakers will need to pay particular attention to the operation of emissions trading in a heavily regulated electricity sector, to cap setting in the context of a national emissions intensity target and related price developments given uncertainty in underlying emissions growth rates, to the option of auctioning permits and using the proceeds for other purposes, and to implementing reliable systems for monitoring, reporting and verification of emissions. This paper serves as an introduction to the special issue "Emissions trading in China" and draws on insights from the papers in the special issue.

\section{Introduction}

China is the world's largest emitter of greenhouse gases. Its economy is growing fast, energy intensity is high, and energy supply is dominated by coal. Consequently, China offers by far the largest potential for emissions reductions of any nation. China's leadership has progressively strengthened its commitment to climate change mitigation. Although China insists on the principle of common but differentiated responsibilities in the international climate negotiations, at home China is implementing ambitious policies to improve energy efficiency and switch from coal to cleaner energy sources, including renewable power. This is in line with a belief in the existence of global climate change by the vast majority of Chinese (Dai et al. 2014)

Climate policy goes hand in hand with other Chinese policy objectives, in particular reducing local air pollution, improving energy security and attaining a leadership position in advanced manufacturing technologies. Various targets to 2020 for emissions, energy use and energy technologies reflect this. China appears on track to achieving these existing targets to 2020 , but action commensurate with strong global climate change mitigation during the following decade will require a continued and increasing policy effort. 
Until recently, the Chinese climate policy repertoire has consisted almost exclusively of regulatory interventions, as well as state-directed investment. But China is preparing to give a role to market-based mechanisms for emissions control. Seven emissions pilot schemes covering over 260 million people got underway during 2013 and 2014. The central government has announced that a national emissions trading scheme (ETS) will be implemented before 2020, and analysis on its design is understood to be underway. In creating such a scheme, China can draw on extensive international experiences, starting with the EU ETS, as well as the (now revoked) Australian carbon pricing mechanism, the Californian ETS, and schemes in Canada, the US East Coast states, and New Zealand.

But making emissions pricing effective in China is incomparably more difficult than in any of the national and sub-national schemes already in operation. China's economy still has strong elements of state control, and regulation is ubiquitous in the energy sector. Effective and cost-efficient emission pricing can only be achieved with energy market reform. And ahead of comprehensive market reform, there are complex challenges to be addressed.

In this paper, we review emerging experiences with ETS in China and lessons from international experience, and draw some conclusions for the design of a national ETS for China. We base our review in large part on findings from the papers in this Special Issue of Energy Policy, which arose out of ongoing collaborations with researchers in China and developed countries including a workshop at the Centre for European Economic Research (ZEW) in Mannheim in November 2012 were most of the papers were presented.

This paper is organized as follows. In Section 2 we discuss China's emissions trends and targets, and underpinnings of China's climate change policy. In Section 3 we review the design and early insights about the operation of some of the emissions trading pilot schemes. In Section 4 we review lessons from international emissions trading schemes that are of relevance to China. Section 5 concludes.

\section{Emissions trends, targets and underpinnings of China's climate policy}

\section{Emissions trends and targets}

China has been the world's largest emitter of carbon dioxide since 2006. In 2011, China accounted for 21 per cent of global energy demand, 49 percent of global coal use by energy content and 26 percent of global energy-related carbon dioxide emissions (IEA 2013a, b). China's carbon dioxide emissions rose by 140 per cent between the year 2001 and 2011, on account of China's exceptionally rapid economic growth, the energy intensive nature of economic growth during that particular period, and the fact that the carbon intensity of energy supply remained practically unchanged. China's emissions growth has slowed in recent years and emissions intensity of the economy since 2005 is on a declining trend in line with China's target to reduce emissions intensity by 40 to 45 per cent from 2005 to 2020 (Table 1).

China's economy is highly carbon intensive. Carbon dioxide output per dollar of GDP, adjusted for purchasing power in 2011, was twice that of the United States and three times that of Europe - and even higher for GDP at exchange rates. The high emissions intensity is due firstly to a comparatively high energy intensity of GDP, on account of a high shares of heavy industries and capital investment, and because of relatively low average efficiency levels in energy use. Secondly, the relatively high carbon intensity of energy supply is driven by the dominance of coal. 
Both aspects provide great potential for improvement of China's emissions intensity, and ultimately reductions in China's absolute emissions levels. Wei et al. (2013) show that great energy and carbon abatement potential exist for Chinese thermal power enterprises. With appropriate policies, a peak in China's carbon emissions in the 2020s or even earlier has been shown to be possible (Jiang 2013, Garnaut 2014). For example, restructuring of growth towards high value manufacturing and services may be in the cards and would cause a significant slowdown in emissions growth even without additional policy effort.

Table 1: China's energy use, CO2 emissions from energy use and GDP, 2005-13

\begin{tabular}{|l|c|c|}
\hline & Annual growth (\%) & Index $(2005=1)$ at 2013 \\
\hline Energy/GDP & $-3.8^{\mathrm{a}}$ & 0.74 \\
\hline $\mathrm{CO}_{2} /$ Energy & $-0.5^{\mathrm{a}}$ & 0.96 \\
\hline $\mathrm{CO}_{2} / \mathrm{GDP}$ & -4.3 & 0.71 \\
\hline $\mathrm{GDP}$ & 10.1 & 2.16 \\
\hline Energy & 6.0 & 1.59 \\
\hline $\mathrm{CO}_{2}$ & 5.4 & 1.52 \\
\hline
\end{tabular}

Sources: IEA (2013b) for data to 2011; Teng and Jotzo (2014) for 2012-2013 data.

\section{China's climate policy framework}

President $X i$ Jinping has stated that China should pursue a new mode of growth to promote 'more efficient, equal and sustainable economic development' (The Economist 2013). This does not appear to be just rhetoric but policy intent, and climate change mitigation plays a prominent part in the attempt to re-define Chinese economic growth.

Climate policy goes hand in hand with other Chinese policy objectives, in particular reducing local air pollution, improving energy security and attaining a leadership position in advanced manufacturing technologies (Boyd 2012). Urban air pollution is taking an increasingly stark toll in terms of health impacts and is driving policies to cut coal combustion in urban areas in the coastal areas and Beijing.

There is also an increasing understanding that reducing the share of fossil fuels in the energy system will reduce the exposure of the economy to energy price shocks, and that higher energy productivity may have positive economy-wide effects (Teng and Jotzo 2014). A host of regulatory interventions to improve energy efficiency and reduce the carbon intensity of China's energy system is in place. One example is the mandatory energy-saving and emission-reduction program launched as part of the 11th National Five-Year Plan (2006-2010), which generated notable improvements in energy efficiency and environmental quality (Levine et al. 2010).

But China is preparing to give a role to market-based mechanisms for emissions control. Seven emissions pilot schemes are in place (see Section 3). The central government has announced that a national emissions trading scheme (ETS) will be implemented before the end of the decade (Zhang et al. this issue). The China-based expert community has a strong expectation that an ETS, and perhaps also a carbon tax, will be in place by the year 2020 (Jotzo et al. 2013). 


\section{Emissions trading in a highly regulated energy sector}

China's leadership has stated that it intends to continue and accelerate the process of giving markets a greater role in the economy, but the challenges of putting the energy sector on a market footing are enormous. Work is underway within the bureaucracy to decide the design parameters of a national ETS. But making emissions pricing effective in China is incomparably more difficult than in any of the national and sub-national schemes already in operation.

China's economy still has strong elements of state control, in particular in the energy sector, which is a key sector for successful emissions trading. Although a gradual process of deregulation is underway, regulation remains ubiquitous, including for energy prices and operational aspects such as dispatch times for power stations, and many of the largest corporate players are state-owned.

Making emissions trading work in these circumstances is a challenge for scheme design (Howes and Dobes 2010, Baron et al 2012). Full effectiveness and costefficiency can only be achieved with energy market reform. Teng et al (this issue) assess the institutional barriers to an effective ETS in China inherent in China's current electricity market model. They find major challenges from the "equal share" dispatching model for power stations and from regulated electricity pricing. They suggest that in the short term, ahead of price liberalization, emissions pricing in China could proceed as a "supply side" model with an "energy saving" model of electricity dispatch from generators. Li et al (this issue) find that rigid electricity prices mean that carbon pricing is less effective than it would otherwise be, but consider that the existing regulated electricity sector is a feasible starting point.

The discussions of a suitable ETS structure for China can also learn from Korea, which is planning a national ETS and where Electricity markets are strictly controlled by governments as well. Park and Hong (this issue) discuss the consequences of cheap electricity price controlled by the government in the implementation of a possible Korean ETS. The strictly regulated electricity price blocks the cost passthrough not only in the electricity trading market but also in the carbon market. This leads to the suggestion to apply intensity measures exclusively for the power sector, while an absolute emission cap is applied to the rest of the regulated sectors. Park and Hong conclude that this type of decoupled rules can never be an effective solution for accomplishing the national abatement target. They call for price deregulation and a focus on the "fundamental spirit of market mechanisms".

In order to achieve market efficiency even in the presence of market imperfections and price and quantity controls in the electricity market, Kim and Lim (this issue) recommend a particular policy mix. They argue that a cap-and-trade regulatory system for indirect emissions combined with relative (intensity) targets for direct emissions can achieve market efficiency. It provides price incentives for consumers to adjust their electricity consumption in line with an efficient allocation of other types of energy. While intensity regulation provides mitigation incentives to power producers, the output subsidy effect of rate-based updating allocation helps prevent the double burden of carbon costs on electricity consumers. Kim and Lim suggest that policy proposals have to be studied carefully to prevent double regulation and higher administrative costs. 


\section{China's ETS pilot schemes}

The Chinese government announced its intent to establish emissions trading in 2011, and moved quickly to establish seven regional emissions trading schemes: in the provinces of Guangdong and Hubei, and the cities of Beijing, Tianjin, Shanghai, Chongqing and Shenzhen. Together, the seven pilot schemes cover a population of over 260 million people and almost 1.8 trillion dollars in 2010 (Zhang et al this issue).

The pilot schemes cover a wide range of different economic circumstances, from Hubei as a relatively less developed region with an economic structure dominated by heavy industry, to the high-income coastal cities of Shanghai, Beijing and Shenzhen whose economies are dominated by services and some manufacturing. Average levels of income, energy use and emissions differ greatly (Table 2).

The design features of some of the pilot schemes are similar in important respects, for example all give out most of the permits for free in the initial stages. But they differ in other important dimensions, for example with regard to the coverage of the schemes, trading rules and provisions for price stabilization. These aspects are explored further below and in several papers in this special issue.

The differences in context and scheme design are deliberate. As Zhang et al (this issue) observe, they are "an important experiment and learning opportunity that will shape a potential future national ETS".

Table 2: Basic indicators for provinces and cities with pilot schemes

\begin{tabular}{|c|c|c|c|c|c|c|c|c|}
\hline & $\begin{array}{l}\text { Populatio } \\
\mathrm{n} \\
\text { (million) }\end{array}$ & $\begin{array}{l}\text { GDP } \\
\text { (RMB } \\
\text { billion) }\end{array}$ & $\begin{array}{l}\text { GDP per } \\
\text { capita } \\
\text { (RMB } \\
1000 \text { 's) }\end{array}$ & $\begin{array}{l}\text { Energy } \\
\text { use } \\
\text { (million } \\
\text { tonnes } \\
\text { SCE) }\end{array}$ & $\begin{array}{l}\text { Energy } \\
\text { use per } \\
\text { capita } \\
\text { (tonnes } \\
\text { SCE/ } \\
\text { person) }\end{array}$ & $\begin{array}{l}\text { Carbon } \\
\text { dioxide } \\
\text { emission } \\
\text { (million } \\
\text { tonnes) }\end{array}$ & $\begin{array}{l}\text { Emis- } \\
\text { sions } \\
\text { per } \\
\text { capita } \\
\text { (tCO2/ } \\
\text { person } \\
\text { /year) }\end{array}$ & $\begin{array}{l}\text { Emis- } \\
\text { sions } \\
\text { intensity } \\
\text { (gCO2/ } \\
\text { RMB) }\end{array}$ \\
\hline $\begin{array}{l}\text { Shenzhen } \\
\text { SEZ }\end{array}$ & 10 & 903 & 87 & 49 & 4.7 & 83.4 & 8.3 & 92 \\
\hline Beijing & 20 & 1182 & 60 & 70 & 3.5 & 103 & 5.2 & 87 \\
\hline Tianjin & 13 & 781 & 60 & 68 & 5.3 & 134 & 10.3 & 172 \\
\hline Shanghai & 23 & 1556 & 68 & 112 & 4.9 & 211 & 9.2 & 136 \\
\hline Chongqing & 29 & 616 & 21 & 79 & 2.7 & 125 & 4.3 & 203 \\
\hline Hubei & 57 & 1250 & 22 & 151 & 2.6 & 320 & 5.6 & 256 \\
\hline Guangdong & 104 & 4016 & 39 & 269 & 2.6 & 444 & 4.3 & 110 \\
\hline China & 1341 & 31234 & 23 & 3895 & 2.9 & 8146 & 6.1 & 261 \\
\hline $\begin{array}{l}\text { Pilot } \\
\text { schemes } \\
\text { combined }\end{array}$ & 256 & 10303 & 40 & 798 & 3.5 & 1253 & 4.9 & 122 \\
\hline $\begin{array}{l}\text { Pilot } \\
\text { schemes } \\
\text { share of } \\
\text { national total }\end{array}$ & $19 \%$ & $33 \%$ & & $20 \%$ & & $16 \%$ & & \\
\hline
\end{tabular}

Source: Jotzo (2013).

\section{Coverage}

An unusual feature in all Chinese pilot ETS is that they cover not just direct emissions from fossil fuel use; but, also emissions attributable to electricity use within each city or province with a pilot scheme, including from electricity generated outside 
the scheme. In the case of some of the city ETS, these indirect emissions account for a large share of emissions covered (Wu et al this issue, Jiang et al this issue, Zhang et al this issue).

In practice, this means that large electricity users - principally manufacturers and large buildings - have a permit liability for their electricity use. Hence, they face a somewhat higher effective electricity price than would otherwise be the case. Their effective electricity price is also higher than the price of their competitors outside of the pilot schemes or those that fall below the size threshold for inclusion. Whether and to what extent this price signal influences operations and investment decisions remains unclear.

The thresholds for coverage vary greatly between schemes, with Hubei having a very high threshold of $120 \mathrm{kt} \mathrm{CO} 2$ per year, and at the other end of the scale Shenzhen with a threshold of just $5 \mathrm{kt}$. This compares to a threshold of $25 \mathrm{kt} \mathrm{CO2-equivalent} \mathrm{in}$ the EU ETS. A higher threshold means a smaller number of participants in the scheme and lower total transaction costs, yet it reduces the share of overall emissions covered by the emissions price.

Shenzhen has implemented the broadest coverage of emissions, including all direct and indirect emissions from all industrial sectors, as well as the buildings and the transport sector. As Jiang et al (this issue) point out, this is a significant innovation. However, it means there is a large number of liable entities (over 800 ) accounting for a relatively modest absolute amount of emissions (32 million tonnes of CO2equivalent per year), with obvious questions about cost-effectiveness.

Hubei meanwhile is the world's third largest emissions trading scheme, even though only 138 emitters are covered by it (Qi et al this issue). Heavy industries including steel, chemicals, refining and cement, along with power generation, dominate the province's economy and the trading scheme.

None of the schemes includes "upstream" coverage, i.e., imposing the liability to acquit permits on the providers of fossil fuels higher up in the supply chain, such as coal mines, oil refineries or gas distributors. This approach was taken in part of the Australian carbon pricing scheme, namely for the use of natural gas in smaller commercial installations and by households (Jotzo 2012). Upstream coverage can drastically reduce the number of companies covered by a scheme.

Upstream coverage could be an attractive feature for China's national ETS in order to minimize potential problems with emissions monitoring and verification. But this relies on upstream fuel suppliers being able to pass on the costs of carbon permits to their downstream customers. At present this is not consistently the case in China's fossil fuel using industries. In contrast to the EU ETS where installations are the unit of coverage, in the Chinese pilots it is companies that are the legal entity for permit liability.

\section{Cap setting}

The cap (total amount of permits issued) is a key aspect of any ETS. Together with underlying emissions growth and abatement options, it determines the scarcity of permits and hence the trading price. Different approaches have been taken in the pilot schemes.

Some examples illustrate the variety of approaches taken, and the difficulties that pilot schemes have grappled with. The pilot ETS generally do not have clearly defined emissions targets. The province (or city) level emissions targets for 2015 allocated by the central government are not necessarily seen as binding, and in any case the pilot ETS cover only a share of the overall emissions in each province or 
city. Furthermore, there are pressures clearly for the ETS cap not to unreasonably constrain the expansion of industrial activities in the pilot jurisdictions.

Out of this arises an approach whereby caps are constructed in a "bottom-up" fashion from sector-level benchmarks and growth rates, and the total number of allowances issued in this way adds up to the cap in the scheme. This inverts the approach that would normally be taken where the role of an ETS is the principal means of achieving a given overall emissions target; namely, to set a cap first and then allocate permits to emitters.

The Shanghai ETS is an example. As Wu et al (this issue) explain, the allocations for key industries covered by the scheme are calculated according to emission benchmarks (a standardized amount of emissions per unit of production), multiplied by their average activity level over the period 2009 to 2011 . The local government retains discretionary powers however, as it can adjust the allowances to industries and companies according to a range of factors.

Shenzhen has opted for a more complex model of an intensity-based cap determined on the basis of sector-level targets for emissions intensity reduction, benchmarks, and projections of future output (Jiang et al this issue). This provides an automatic stabilizer, as the cap will expand in line with projected output in the following year. The Hubei scheme adopts a 'hybrid' system of cap determination, based on projected growth as well as the possibility of adjustments to the cap, however here this is based on ex-post adjustment in light of realized activity levels (for power generators) (Qi et al this issue).

\section{Permit allocation}

All pilot schemes to date have allocated the large majority - or all of - the permits for free to companies that are covered by the schemes. Several of the schemes retain a small share of the overall amount of permits as a reserve, to be issued into the market if the market price were to become unexpectedly or unacceptably high. Such an "allowance reserve" is a feature also in the Californian ETS.

There are strong arguments in favor of auctioning a significant share of the permits and for governments to use the revenue to support other programs or to lower other taxes. This is done in the third phase of the EU ETS and as was done from the start of the Australian and Californian schemes. Numerous theoretical and empirical modelling analyses have shown that well targeted revenue recycling can reduce the economic costs of achieving emissions reductions through ETS or carbon taxes. In some cases, there may even be a "double dividend" of economic gains as well as environmental gains (Goulder 1995).

For China's case, this is illustrated with simulations of a reduction in consumption and production taxes, paid for out of carbon pricing revenues ( $\mathrm{Li}$ et al this issue). They point out, however, that their optimal policy settings can only be achieved under a de-regulated electricity market, allowing carbon cost pass through from generators to electricity users. Cao (2013) also found significant potential benefits of different forms of tax change in China linked to the revenues from a carbon tax.

Nevertheless, for the Chinese pilot schemes, it appears that the revenue-raising prospects of the schemes have not been an important consideration in the face of concerns about impacts on the profitability of companies covered by the schemes. It is commonplace for companies to exert political pressure on governments for the issuance of free permits under emissions trading schemes. Equally, however, once it is observed that an ETS does not have a significant adverse effect on industry, this can open the door to auctioning of permits. 
To what extent permits will be auctioned and revenue retained, and which emitters will be given free permits and on what basis, is a key consideration for a national ETS. Hübler et al (this issue) analyses the impacts of the introduction of a national ETS in China on energy-intensive and trade-exposed industries as they are potentially prone to carbon leakage, i.e. their relocation to countries with less strict climate policies. While several sectors are affected only moderately by the introduction of an ETS, some industries (e.g. electricity, aluminum, other non-ferrous metals) experience non-negligible production losses. Full auctioning of allowances leads to much greater sectoral output reductions. At the macroeconomic level, the sectoral output reductions are compensated by revenues from auctioning. The choice between auctioning and free allocation of allowances has only minor implications for the Chinese macroeconomy given lump-sum revenue transfers.

\section{Implementation of the pilot schemes}

The time from announcement to implementation of the Chinese pilot schemes was short relative to international experience such as the EU ETS and Australia. The relatively fast startup of the pilots is remarkable in light of the fact that very little preexisting institutional knowledge and few experts were available, and that there are significant hurdles to overcome regarding overlapping jurisdictions and the absence of monitoring of emissions levels and monitoring procedures.

Not all of these issues are addressed fully at the start of pilot schemes, with further learning being a deliberate aspect. This has led to some uncertainties affecting the operation of the schemes. As Wu et al (this issue) point out for the case of Shanghai, there are significant uncertainties in the pilot schemes, arising from cap setting procedures, their relationship to growth trajectories, the extent of emissions reductions possible, as well as the largely untested provisions for monitoring, reporting and verification.

To some extent, such uncertainties are unavoidable at the start of an ETS. The 'pilot' nature of the existing regionally based ETS makes allowance for such uncertainties. Experience accumulates rapidly in the pilots, and can inform the design of a national scheme. In other respects, the lack of clarity results in avoidable policy uncertainty. Governments can minimize uncertainties by fully spelling out the provisions for the scheme, especially scheme caps and/or the rules that will determine scheme caps in future years.

Trading volumes have been relatively low in the first months of operation of most of the pilots. Indications that liable entities are treating the schemes largely as compliance markets, as evident in a spike in trading volumes just before the due date for permit acquittal in the Beijing scheme. The exception is Hubei, where trading is open to financial investors, and where institutional investors were allowed to take part in the first round bidding before the start of the market (Qi et al this issue).

Finally, institutional and operational aspects are crucial to the successful implementation. In particular, monitoring, reporting and verification of emissions has presented major difficulties in the pilot ETS. The necessary frameworks and procedures on the whole did not exist at the introduction of the pilots, and systems are being refined during the operation of the pilots. A national scheme will be able to draw on the practical experiences being made in the pilot schemes. 


\section{Insights for a national scheme from international experience}

In developing a national ETS, China can observe experiences and draw on a large body of analysis done on options for and features of existing ETS in Western countries. In this special issue, some issues of international experience of potential relevance for China are covered.

\section{Uncertainty and policy interaction}

Unexpectedly low prices and reduction efforts now characterize the EU ETS, since the decline in European economic growth rates and growth outlook in the early 2010s, and given strong regulatory and subsidy policies in some European countries. As de Perthuis and Trotignon (this issue) argue, the EU ETS "has been undermined variously by the weakness of its regulation, an undesirable overlap with other public policies and the far-reaching economic and financial crisis that caused the market price of allowances to plunge."

One important aspect of the EU experience has been the interaction of the ETS with other policies that also serve to reduce emissions, and so reduce efforts required to stay within the cap prescribed by an ETS. Flues et al (this issue) investigate the effects of alternative scenarios for electricity demand, and interactions between the EU ETS and renewable energy support policies. They find that there can be severe and costly consequences of policy interaction when aggregate electricity demand is low, and that the presence of fixed renewable energy support policies makes ETS permit prices more sensitive to changes in economic activity.

\section{Cap setting}

In an ETS, a pre-announced future trajectory of caps assists market predictability. On the other hand, a fixed trajectory of caps may result in the scheme requiring unexpectedly greater mitigation efforts, at higher than expected permit prices, if underlying emissions growth is higher than expected; or unexpectedly lower efforts and prices if underlying growth is weak.

If China's cap were set according to an intensity standard, the economic growth related uncertainty about permit prices could be reduced. Hübler et al (this issue) evaluate policy design options for a China ETS taking into account uncertainty about future growth. In their simulations higher Chinese economic growth slightly increases mitigation costs under the intensity target in 2020. However, under the fixed emissions cap in 2030, the results are sensitive to the assumptions on Chinese economic growth..

There are different views on whether unexpectedly low or high prices are a problem to be rectified or not. A large literature argues that a hybrid approach between price and quantity control is desirable. This could be achieved through a combination of price floor and price ceiling, keeping the permit price in a corridor. California's scheme has a price floor implemented by way of reserve price at auction, and a price floor was also planned for the Australian scheme. Most ETS have an implicit price ceiling in the form of a compliance penalty. Given large uncertainties about China's future underlying emissions trajectory, the effect of other policy measures and the response of the economy to a carbon price, an argument can be made for price corridors (price floors and ceilings) in a Chinese national ETS (Jotzo 2013).

Another approach is for caps to be adjusted in light of market, economic and technological developments. Australia had a system of "rolling caps" whereby a trajectory of caps was fixed for five years, with indicative caps beyond this time, and an independent authority to advise government on the setting of the cap each year beyond that. 
De Perthuis and Trotignon (this issue) argue for an approach that hands the setting of caps to an independent authority, which has full regulatory powers and acts according to a governance framework and clearly expressed long term goals, but full discretion for the authority to react to short term. There are parallels with the setting of monetary policy by a central bank.

\section{Conclusions}

China's planned move towards national emissions trading is a highly ambitious undertaking. It is fraught with difficulty as it takes place in a still highly regulated energy sector and in the context of a host of regulatory policies to constrain emissions growth. At the same time, it provides great opportunity for China's environmental policy to be based on market instruments, and for China to take global leadership on putting a price tag on pollution.

The emissions trading pilot schemes now underway in China can provide valuable experiences for the design of a national scheme. Likewise, China can benefit from the experiences made with emissions trading in Western countries.

In this paper, we summarize some of these emerging experiences, with a focus on recapitulating and interpreting the insights from papers in this special issue of Energy Policy, 'Emissions trading in China'.

We find that policymakers will need to pay particular attention to the operation of emissions trading in a heavily regulated electricity sector. Setting emission caps in the context of a national emissions intensity target creates specific difficulties.

Related price developments are uncertain and depend to a large extent on underlying emissions growth rates. The option of auctioning permits and using the proceeds for other purposes is not taken into consideration extensively. Finally, implementing reliable systems for monitoring, reporting and verification of emissions remains a major task for policymakers in China.

Acknowledgments: We thank the authors of papers in this Special Issue, the editors of Energy Policy, the Elsevier team around Carrie Palmer, and Benjamin Lutz from ZEW for their support. Participants at workshops at Tsinghua University, Centre for European Economic Research (ZEW) Mannheim and the Australian National University provided valuable feedback. Grants by the Robert Bosch Foundation under the program "Sustainable Partners - Partners for Sustainability", the Australian Research Council and the Australian government supported different parts of the project. 


\section{References}

Baron, R., Aasrud, A., Sinton, J., Campbell, N., Jiang, K., \& Zhuang, X. (2012), Policy Options for Low - Carbon Power Generation in China: Designing an Emissions Trading System for China's Electricity Sector, International Energy Agency, Paris.

Boyd, O. (2012), China's energy reform and climate policy: the ideas motivating change, CCEP Working Paper No. 1205, Centre for Climate Economics and Policy, Crawford School of Public Policy, The Australian National University, Canberra.

Cao, J. (2013), 'Exploring carbon tax in China', in: Gang, F., Stern, N., Edenhofer, O., Xu, S., Eklund, K., Ackerman, F., Li, L. and Hallding, K., eds, The Economics of Climate Change in China: Towards a Low-Carbon Economy, Earthscan, pp. 213-30.

Dai, J., Kesternich, M., Löschel, A. and Ziegler, A. (2014), 'Do Chinese individuals believe in climate change and why? An econometric analysis', MAGKS Discussion Paper No. 28-2014.

De Perthuis, C. and Trotignon, R. (this issue), 'Governance of CO2 markets: Lessons from the EU ETS', Energy Policy.

Flues, F., Löschel A., Lutz, B. and Schenker, O. (this issue), Designing an EU energy and climate policy portfolio for 2030: Implications of overlapping regulation under different levels of electricity demand, Energy Policy

Garnaut, R. (2014), 'China's Role in Global Climate Change Mitigation', China \& World Economy, forthcoming.

Goulder, L. H. (1995), 'Environmental taxation and the double dividend: A reader's guide', International Tax and Public Finance 2 (2), pp. 157-83.

Howes, S. and Dobes, L. (2010), Climate Change and Fiscal Policy: A Report for APEC, Washington, DC: The World Bank.

Hübler, M., Voigt S., Löschel, A. (this issue), Designing an emissions trading scheme for China-An up-to-date climate policy assessment, Energy Policy

International Energy Agency (IEA) (2013a), CO2 Emissions Indicators 2013, Paris: International Energy Agency.

International Energy Agency (IEA) (2013b), World Energy Outlook 2013, Paris: International Energy Agency.

Jiang, K., Zhuang, X., Miao, R. and He, C. (2013), 'China's role in attaining the global $2^{\circ} \mathrm{C}$ target', Climate Policy 13 (sup01): 55-69.

Jiang, J.J., Ye, B. and Ma, X.M. (this issue), 'The construction of Shenzhen's carbon emission trading scheme', Energy Policy.

Jotzo, F. (2012), 'Australia's carbon price', Nature Climate Change 2(7): 475-476.

Jotzo, F., D. de Boer and H. Kater, 2013, "China carbon pricing survey 2013," CCEP Working Paper No. 1305, Centre for Climate Economics and Policy, Crawford School of Public Policy, The Australian National University, Canberra.

Jotzo, F. (2013), "Emissions trading in China: Principles, design options and lessons from international practice," CCEP Working Paper No. 1303, Centre for Climate Economics and Policy, Crawford School of Public Policy, The Australian National University, Canberra.

Kim, Y.G. and Lim, J.S. (this issue), 'Emissions Trading Scheme Design for Power Industries Facing Price Regulation', Energy Policy. 
Levine, M. D., Price, L., Zhou, L., Fridley, D., Aden, N., Lu, H., McNeil, M., Zheng, N., Qin, Y., and Yowargana, P. (2010), Assessment of China's Energy-Saving and Emission-Reduction Accomplishments and Opportunities During the 11th Five Year Plan. Lawrence Berkeley National Laboratory: Berkeley, CA.

Li, J., Wang, X., Zhang, Y., Kou, Q. and Cai, S. (this issue), The economic impact of carbon pricing with regulated electricity prices in China - an application of a Computable General Equilibrium approach, Energy Policy.

Park, H. and Hong, W.K. (this issue), 'Korea's Emission Trading Scheme and Policy Design Issues to Achieve Market-Efficiency and Abatement Targets', Energy Policy.

Qi, S., Wang, B. and Zhang, J. (this issue), 'Policy Design of the Hubei ETS Pilot in China', Energy Policy.

Teng, F. and Jotzo, F. (2014), 'Reaping the Economic Benefits of Decarbonization for China', China \& World Economy, forthcoming.

Teng, F., Wang, X. and Zhiqiang, L.V. (2014), 'Introducing the emissions trading system to China's electricity sector: Challenges and Opportunities', Energy Policy...

The Economist (2013), 'The party's new blueprint', The Economist, 16 November 2013. Available from http://www.economist.com/blogs/analects/2013/11/reform-china

Wei, C., Löschel, A. and Liu, B. (2013), An Empirical Analysis of the CO2 Shadow Price in Chinese Thermal Power Enterprises, Energy Economics 40, 22-31.

$\mathrm{Wu}, \mathrm{L} .$, Quian, H. and Li, J. (this issue), 'Advancing the experiment to reality: Perspectives on Shanghai pilot carbon emissions trading scheme', Energy Policy.

Zhang, D., Karplus, V. J., Cassisa, C. and Zhang, X. (this issue), 'Emissions trading in China: progress and prospects', Energy Policy. 